\title{
Comparing Dictionary-induced Vocabulary Learning and Inferencing in the Context of Reading
}

\author{
Di Zou, English Language Centre, The Hong Kong Polytechnic University,
} Hung Hom, Hong Kong (dizoudaisy@gmail.com)

\begin{abstract}
This research examines dictionary-induced vocabulary learning and inferencing in the context of reading. One hundred and four intermediate English learners completed one of two word-focused tasks: reading comprehension and dictionary consultation, and reading comprehension and inferencing. In addition to performing the tasks, some subjects reported their thinking processes either during or after the completion of the tasks, and those who did not were tested both immediately and one week later for their learning of target words. The results show that dictionary-induced vocabulary learning was significantly more effective than inferencing. The researcher explains such results in terms of theories of the degree of elaboration and connectionist models, and suggests that the provision of a number of various aspects of knowledge about a target word is very facilitative for word learning.
\end{abstract}

Keywords: DICTIONARY, DICTIONARY-INDUCED VOCABULARY LEARNING, INFERENCING, WORD LEARNING, ELABORATION, CONNECTIONIST, CONNECTIONS, TASK, WORD KNOWLEDGE, EFFECTIVENESS

Opsomming: Vergelyking van woordeboek-gemotiveerde aanleer en -afleiding van woordeskat in die leeskonteks. Hierdie navorsing ondersoek woordeboekgemotiveerde aanleer en -afleiding van woordeskat in die leeskonteks. Eenhonderd-en-vier intermediêre Engels leerders het een van twee woordgefokusde opdragte voltooi: leesbegrip en woordeboekkonsultasie, en leesbegrip en betekenisafleiding. Buiten die uitvoer van die take, het party proefkonyne ook tydens of ná voltooiing van die take verslag gedoen van hul denkprosesse, en dié wat dit nie gedoen het nie is onmiddellik, asook een week later, getoets vir die aanleer van teikenwoorde. Die resultate toon dat woordeboek-gemotiveerde aanleer van woordeskat beduidend effektiewer was as betekenisafleiding. Die navorser verduidelik hierdie resultate aan die hand van teorieë van die graad-van-uitbreidingsmodel en die konneksionistiese model, en stel voor dat die voorsiening van 'n aantal verskillende kennisaspekte van ' $n$ trefwoord die aanleer van woorde baie vergemaklik.

Sleutelwoorde: WOORDEBOEK, WOORDEBOEK-GEMOTIVEERDE AANLEER VAN WOORDESKAT, BETEKENISAFLEIDING, AANLEER VAN WOORDE, UITBREIDING, KONNEKSIONISME, KONNEKSIES, OPDRAG, WOORDKENNIS, EFFEKTIWITEIT 


\section{Introduction}

As vocabulary is one of the crucial components of a language, an increasing amount of research on second language acquisition has concentrated on vocabulary acquisition. Word knowledge generally involves knowledge of the form, meaning and use, and dictionary consultation and inferencing are two of the most frequently investigated approaches to the learning of word meaning (Nation 2001).

\subsection{Dictionary-induced Vocabulary Learning}

A great deal of controversy exists over the facilitative effects of dictionary consultation. On the one hand, some researchers argue that using a dictionary while reading leads to inefficient learning (Chan 2011), or extra time spent on looking up words was unlikely to be used efficiently (Knight 1994). It does not always improve comprehension (Koyama and Takeuchi 2004); or looking up too many words without careful consideration led to shallow processing and short-term retention (De Ridder 2002). Prichard's (2008) explanations for such results are that dictionary use was facilitative for less proficient learners because it can help them reach the comprehension threshold; proficient learners, however, already knew enough words in the passages to enable comprehension, so the benefits were reduced. After examining dictionary assistance for learners' identification and retention of collocations, Laufer (2011) concluded that learners sometimes had challenge of identifying the correct verbs, but often they regarded dictionary consultation unnecessary.

On the other hand, many researchers believe that dictionary consultation assists reading comprehension and promotes word knowledge development. Luppescu and Day (1993), Hulstijn, Hollander and Greidanus (1996), Abraham (2008), Dziemianko (2010), Chen (2011), Liu and Lin (2011), Chiu and Liu (2013), and Nation (2015) all found significant facilitative effects of dictionary consultation for word learning. Dictionary use is important for learning the correct use (Chan 2012), meanings (Lew 2012, Coffey 2011), and spellings of target words (Liu et al. 2014). It is beneficial to learners whose language proficiency is neither too high nor too low (Prichard 2008).

\subsection{Inferencing}

Inferencing, which asks learners to guess the meaning of an unknown word according to its context, is closely associated with vocabulary learning (Nassaji 2004) and has its basis in the availability of linguistic and non-linguistic cues in the text (Hu and Nassaji 2012). The facilitative effects of inferencing on word learning have been noted by many previous studies, for example, Hulstijn (1992), Nation (2001), Pulido (2009), Nassaji and Hu (2012), Carpenter et al. 
(2012), and Webb and Chang (2015). Huang and Lin (2014) examined three approaches to glossing and also found that the inference-gloss-gloss condition was more effective than full glossing condition. Nevertheless, Sadoski, Goetz and Rodriguez (2000) argued that although inferencing led to good immediate recall of word meanings, it promoted little retention. Mondria (2003) also pointed out that inferencing was considerably more time-consuming but did not lead to better learning than the meaning-given method.

Compared to dictionary-induced vocabulary learning, inferencing is believed to be less effective in promoting word learning (e.g. Knight 1994, Liu et al. 2014, Nation 2015). However, the involvement load hypothesis, which argues that the retention of words is conditional upon three factors in a task: need, search and evaluation, simply defines search as the attempt to find the meaning or form of target words and allocates the same involvement load to various approaches to it (Laufer and Hulstijn 2001). It is therefore necessary to conduct a direct test on the effectiveness of different approaches to search from the perspective of the involvement load hypothesis, the results of which may shed light into further development of this hypothesis.

\subsection{Objectives and Research Questions of this Research}

This research aims at two objectives: to examine whether dictionary-induced vocabulary learning and inferencing would promote initial learning and retention of target words with similar effectiveness, and to inspect how they would differ from each other with regard to the processing of target words by learners.

Two questions are raised accordingly. (1) Does reading comprehension and dictionary consultation promote word learning with similar effectiveness as reading comprehension and inferencing? (2) What are the reasons for any similarity or difference detected?

\section{Method}

\section{$2.1 \quad$ Tasks}

The present research investigated two tasks. Task 1: reading comprehension and dictionary consultation asked the subjects to read a text, look up the ten underlined words in the dictionary and complete ten multiple-choice questions. The Longman Dictionary of Contemporary English, 5th Edition (2009) was used because firstly it is a monolingual dictionary and meets the requirement of eliminating the influence of translation from Chinese in the task, and secondly the participants in this research noted that it was one of their most commonly used dictionaries. 
Task 2: Reading comprehension and inferencing, as demonstrated in Appendix 1, required the subjects to read the same text, infer the meanings of the ten underlined words according to their contexts, write down the inferred meanings in the margin of the text, and complete three multiple-choice questions. These questions were different from those for Task 1 in that they were designed to inquire about the general gist of the whole text, rather than specifically require knowledge of the target words, because the inferencing exercises had already imposed the search for the meanings of those words.

Each of the participants in this research was randomly asked to complete one of the two tasks and strictly follow the requirements. As the task completion time was inherent to the nature of the tasks, I did not attempt to make the completion time the same for different learners doing different tasks so as to avoid deliberate manipulation of the completion time for the two tasks. Also, although these two tasks are different in respect to the multiple-choice questions and the way the target words were processed by the participants, these differences relate closely to and result from the diverse nature of the two approaches to search that are induced by the two tasks. The main significant difference between the two tasks, therefore, can be regarded as the two approaches to search: dictionary consultation and inferencing.

\subsection{Subjects}

A total of one hundred and four non-English major freshmen at Tsinghua University participated in the research. All of them had learnt English for at least ten years and had obtained scores ranging from 425 to 450 out of 710 in a Chinese national English proficiency exam named College English Examination Band 4 three months before participating in this study. Scores of 450 in this exam are approximately equivalent to a 5.5 score for IELTS.

\subsection{Procedure}

During task completion, eight subjects doing Task 1 and six doing Task 2 were randomly selected to answer introspective questionnaires to reflect their thinking process while doing their assigned tasks (see Table 1). Also, six subjects doing Task 1 and eight doing Task 2 were selected to do think-aloud to record how they tackled the tasks. These participants were allowed to report their thinking process either in English (the target language) or Chinese (their first language).

After task completion, six subjects doing Task 1 and six doing Task 2 were randomly selected to take part in retrospective interviews about their thinking processes during task completion. 31 subjects doing Task 1 and 33 doing Task 2 were tested immediately to measure their initial learning of the target words. One week later, the subjects were unexpectedly tested again to examine their 
retention of the target words in a delayed posttest. During these posttests, the subjects were not allowed to refer to the task materials they had just been working on.

\begin{tabular}{|l|l|c|c|}
\hline & & $\begin{array}{c}\text { Task 1: } \\
\text { Dictionary consultation }\end{array}$ & $\begin{array}{c}\text { Task 2: } \\
\text { Inferencing }\end{array}$ \\
\hline \multirow{2}{*}{ During task } & $\begin{array}{l}\text { Introspective question- } \\
\text { naires }\end{array}$ & 8 & 6 \\
\cline { 2 - 4 } & Think-aloud protocols & 6 & 8 \\
\hline \multirow{2}{*}{ After task } & Retrospective interviews & 6 & 6 \\
\cline { 2 - 4 } & Posttests & 31 & 33 \\
\hline
\end{tabular}

Table 1: Allocation of subjects to tasks

\subsection{Materials}

Materials for the two tasks include mainly the reading text and the target words. The text "Coping with Procrastination" which was also used in Zou's (2016) study was selected as the original text as experience in procrastination was likely to be similarly familiar to all participants. Working within the context of this text, ten target words (divulge, renege, taunt, lassitude, trait, apprehensive, assiduous, indispensable, ostensible and pernicious) were selected. Words with both concrete and abstract meanings were included, with the purpose of removing any possible concreteness effect (Salsbury et al. 2011, Mestres-Missé et al. 2014). Also, the words selected had only a single meaning for the part of speech in which it occurred in the reading text.

A pretest, which asked the 104 participants to write down meanings of the target words and generate original sentences using these words, was conducted three weeks before the experiment, the results of which showed that all participants had very little pre-knowledge of the target words.

\subsection{Assessment and Scoring}

In the immediate and delayed posttests, the participants were provided with a list of the target words and asked to write down the meanings of the words, either in English or Chinese, and generate original English sentences using them. The scoring criteria of the answers to the meanings of the target words had its foundation on those developed by Hulstijn and Laufer (2001) and Keating (2008). (1) A score of 0 was given to an answer with a completely incorrect meaning (e.g. the answer "last long" for the meaning "lassitude"). (2) A half score of 0.5 was given to a semantically acceptable equivalent of the target word (e.g. "negative" for "pernicious"). And (3) a full score of 1 was given to an 
answer with a comparable meaning to that of the target word (e.g. "reveal" for "divulge").

Regarding the sentences, the criteria used in the studies of Paribakht and Wesche (1993), Hulstijn and Laufer (2001), and Zou (2016) were employed. (1) A score of 0 was given to a sentence that had a completely inappropriate semantic context for the target word (e.g. "I'll never forget how badly he traited me."). (2) A half score of 0.5 was given to a sentence that had an appropriate semantic context for the target word but the target word was used ungrammatically (e.g. "The students who have let days off should now apprehensive about their scores of this exam."). And (3) a full score of 1 was given to a sentence with an appropriate semantic context for the target word and the target word was used grammatically (e.g. "Her contribution is indispensable for the success of this project.").

The subjects' answers in both posttests were blindly and separately scored by the author and another trained rater. In cases where it was difficult to decide on an appropriate score, the two raters negotiated the score in collaboration until consensus was reached. Such cases were, however, very rare (fewer than $2 \%$ ). Pearson's $\mathrm{r}$ for the inter-rater reliability was .94 for the immediate posttest and .92 for the delayed posttest.

\subsection{Analysis of the Self-reporting Data}

All self-reporting data were typed up and transcribed into Word documents. As the subjects answered questionnaires in either Chinese or English, and the two self-reporting protocols were conducted in either language, the transcriptions were correspondingly in either language. The Chinese transcriptions were also translated into English for reporting. This stage of data transcription assisted the researcher to not only gain a holistic view of all qualitative data collected but also identify distinct features of the data.

The next stage of data coding involved three main steps: (1) skimming the questionnaire answers and transcriptions to note the elements that the subjects found facilitative for word learning; (2) reviewing relevant literature to identify theories that provided explanations for the facilitative elements; and (3) re-examining the data and paying close attention to the types of thinking processes involved so as to identify reasons for the facilitative effects of these thinking processes and the extent to which these processes promoted word learning. Regarding the thinking patterns of the subjects, I read the transcripts very carefully to identify any expressions that were noted and repeated by different participants in similar contexts.

\section{Results}

The descriptive statistics for the two posttests of the 64 subjects, as displayed in 
the following Table 2, demonstrated that the mean scores of subjects doing Task 1: reading comprehension and dictionary consultation was 12.11 in the immediate posttest and 8.98 in the delayed posttest. And the mean scores of subjects doing Task 2: reading comprehension and inferencing was 7.91 in the immediate posttest and 5.45 in the delayed posttest. The results also showed that subjects obtained great gains of knowledge about the target words after doing these two tasks, given that their pre-knowledge of these words was almost zero.

\begin{tabular}{|c|c|c|c|c|c|c|c|}
\hline & & \multicolumn{2}{|c|}{ Pretest } & \multicolumn{2}{c|}{ Immediate posttest } & \multicolumn{2}{c|}{ Delayed posttest } \\
\cline { 3 - 8 } & $\mathbf{N}$ & $\mathbf{M}$ & SD & $\mathbf{M}$ & SD & $\mathbf{M}$ & SD \\
\hline $\begin{array}{c}\text { Task 1: } \\
\text { Dictionary consultation }\end{array}$ & 31 & 0.16 & 0.37 & 12.11 & 4.22 & 8.98 & 4.99 \\
\hline $\begin{array}{c}\text { Task 2: } \\
\text { Inferencing }\end{array}$ & 33 & 0.18 & 0.39 & 7.91 & 4.70 & 5.45 & 3.95 \\
\hline
\end{tabular}

Table 2: Descriptive statistics of the subjects' scores in the pretest, immediate and delayed posttests

To further test whether dictionary consultation was significantly more effective than inferencing, two independent samples tests were applied, following the standard practices of Hulstijn and Laufer (2001), Keating (2008), and Eckerth and Tavakoli (2012). Statistically significant differences were identified both in the Welch test results concerning the immediate posttest $(t=3.75, d f=62, p<$ .01 , Cohen's $d=.94)$ and in those concerning the delayed posttest $(t=3.14, d f=$ $62, p<.01$, Cohen's $d=.79$ ).

\section{Discussion}

With an attempt to figure out how dictionary-induced vocabulary learning differs from inferencing, the thinking processes of the subjects doing these two tasks were analyzed from two perspectives: the diverse degrees of elaboration entailed by the two tasks and the diverse complexity of connections that make up the networks of target words.

\subsection{Degree of Elaboration}

Depth of processing examines different types or levels of information processing from a qualitative perspective, arguing that the chance of a piece of infor- 
mation being stored in long-term memory depends on the depth with which it is initially processed rather than the length of time that it is held in short-term memory (Craik and Lockhart 1972). Elaboration of encoding, within each qualitative type or any one level of processing depth, investigates information processing from a quantitative perspective (Craik and Tulving 1975). It is the degree to which each type of processing has been enriched during encoding, and refers to the richness or extensiveness of information processing (Craik 2002).

Both dictionary consultation and inferencing involve semantic processing of information about target words, as both entail attempts to find out diverse information of a target word, thus they should be at the same level of processing depth. However, they differ in their degrees of elaboration in that dictionaries provide richer information about target words and hence dictionaryinduced vocabulary learning is likely to entail a greater degree of elaboration than inferencing, when a learner consults different features of a word in the dictionary. Empirical support for this assessment can be found in the subjects' answers to the introspective questionnaires, transcripts of think-aloud protocols and retrospective interviews, extracts of which will be provided accordingly as follows.

Dictionaries always provide various aspects of knowledge about words, including such information as pronunciation, part of speech, definition, sample sentences, usage labels (e.g. formal, informal, taboo, etc.), sense relations, and so on. With the advantage of being provided with more information, most participants, who did reading comprehension and dictionary consultation in this experiment, made full use of the available information and processed as much as possible in order to facilitate their comprehension of the target words and the reading text. The following think-aloud transcripts of two subjects doing reading comprehension and dictionary consultation demonstrate that in searching a word's meaning through dictionary consultation, the subjects paid close attention to different aspects of information about the target words, such as its form, spelling, pronunciation, part of speech, definition, and sample sentences:

Or are you picturing that others taunt ... t-a-u-n-t, a-u-n, a-u-n-t ... taunt ... verb, $\mathrm{VN}$, nontransitive ... to try to make somebody angry or upset by saying unkind things about them, laughing at their failures, The other kids continually taunted him about his size ... Taunt ... Or are you picturing that others taunt you about your accent?

You might delay preparing for an oral presentation, because you are apprehensive ... a-p-p-r-e ... apprehensive ... about, of something, that ... worried or frightened that something unpleasant may happen. I was a little apprehensive about the effects of what I had said... You have no reason to be apprehensive of the future ... similar to worried ... apprehensive, worried ... because you are apprehensive that you will not be able to remember the entire speech. 
Illustrations like these can be found in many other think-aloud transcripts of subjects doing reading comprehension and dictionary consultation (see Zou, 2012, for details). These findings may be different from the observations of some researchers who noted that dictionary users were selective in what they read. However, it is worth pointing out that the majority of the participants in their studies were not Chinese learners of English. Studies that were conducted among Chinese learners, nevertheless, found that diverse aspects of knowledge of target words were consulted by the participants. For example, Chen (2010) reported consultation of pronunciation; Chen (2011) and Chan (2012) noticed consultation of usage information.

In contrast to the above findings concerning dictionary consultation, learners who inferred a word's meaning based on a reading text normally have no access to many aspects of knowledge about target words. Beyond inferring the grammatical category and possible meaning of a target word in the given context, it is unlikely that they can acquire any definite knowledge about the words' pronunciation, derivatives, or other collocational possibilities other than that in the sole example in the reading text. It is clearly showed, in the interview transcripts of the subjects who did reading comprehension and inferencing, that they were only able to infer a word's meaning using the limited context provided by the reading text, and that inferring any information other than the meaning was difficult if not impossible. The following transcript is one piece of evidence:

I don't know how the words should be pronounced or used, because such information is not given. I even haven't thought about this, because it is not demanded by the task. I do not know anything else about these words other than their meanings in the given contexts, because nothing else is provided. I haven't thought how the words can be pronounced or used with other words in other contexts. It's very hard for me to know, or infer, such information based on the limited information given.

Supporting evidence of the assessment that subjects who did dictionary consultation processed more information about the target words than those who did inferencing can also be found in the subjects' answers to the introspective questionnaire for Task 1: reading comprehension and dictionary consultation. The following Table 3 demonstrates the percentages of various types of information that were consulted by the eight subjects who answered the questionnaires while consulting the dictionary. The percentage was calculated by dividing the sum of items being consulted by the sum of items provided in the dictionary. For example, a total of 10 definitions for the ten target words were provided, so the sum is 80 for the eight participants $\left(10^{*} 8\right)$. As the results of the questionnaires showed that all 80 definitions had been consulted, the percentage of definitions being consulted was thus $100 \%(80 / 80)$. Similarly, as a total of 40 synonyms were provided and 38 of them had been consulted, the percentage of synonyms being consulted was $95 \%(38 / 40)$. 


\begin{tabular}{|c|c|}
\hline & Percentage of information being consulted \\
\hline Definition & $100 \%(80 / 80)$ \\
\hline Synonym & $95 \%(38 / 40)$ \\
\hline Part of speech & $84 \%(67 / 80)$ \\
\hline Example sentence or phrase & $83 \%(60 / 72)$ \\
\hline Derivatives & $75 \%(24 / 32)$ \\
\hline Pronunciation & $74 \%(59 / 80)$ \\
\hline Usage information & $58 \%(46 / 80)$ \\
\hline Others & $20 \%(16 / 80)$ \\
\hline
\end{tabular}

Table 3: Percentages of information being consulted

In summary, the percentages of different types of information being consulted were respectively $100 \%$ for definitions, $95 \%$ for synonyms, $84 \%$ for parts of speech, $83 \%$ for example sentences or phrases, $75 \%$ for derivatives, and $74 \%$ for pronunciation (see Table 3). Only the rate of usage information was slightly lower than $60 \%$. It is therefore evident that overall, a substantial amount and range of dictionary information were used by subjects doing reading comprehension and dictionary consultation. This is conducive to word learning although it may be due to reactivity effects.

In addition to the above arguments, another significant facilitative effect on word learning of the processing of rich information about target words, which can also be referred to as extensive elaboration on target words, is its assistance with the comprehension of words meanings. Supporting evidence for this can be found in the interview transcripts of the subjects who did reading comprehension and dictionary consultation. They show that information like synonyms, example phrases, sentences and collocations all contributed to their comprehension of word meanings. When subjects had difficulty in thoroughly understanding the definitions given by the dictionary, the processing of information additional to the definition was helpful in respect to the provision of valuable clues. Many subjects were acutely aware of the assistance provided by the rich information about the target words made available to them through the dictionary entries. Supporting evidence of these arguments can be found in the following transcripts:

I find synonyms for target words very useful. Synonyms can help me to grasp the most important feature of a word's meaning very quickly. Um, and they are very short, just one word, so are easy to be remembered. Take 'indispensable' as 
an example. I understood and memorized its meaning the moment I noticed its synonym 'meticulous'.

I consulted the example phrases because I still felt uncertain about what 'trait' exactly means after reading its definition. So I ... I read the example phrases and their definitions so as to better grasp the word's meaning, and this helped my comprehension. The phrases drew my attention on the word 'personality', and helped me to realize that 'trait' is closely related to 'personality'.

I consulted the example sentences because they provide several different contexts in which the target words can be used. This can give me a more comprehensive understanding of the words.

In contrast, subjects who inferred word meanings were given quite a limited range of information for processing, and the available information was basically restricted to linguistic clues in the text and non-linguistic clues from their personal world knowledge. They felt handicapped by the insufficiency of useful information and often found it difficult to get an exact idea about the meaning of a target word. Moreover, since they were not given any specific information about the word's usage, nor were required to pay attention to this aspect, they did not attempt to obtain any information of this type. Supportive evidence of these can be identified in the following transcripts:

I think pernicious refers to something negative. Because here the writer explains that if you procrastinate, you will not have time to do satisfying work, and this will make other people unhappy and get a bad impression of you. And it can even damage your friendships. All of these talk about something bad ... But I am not sure about its meaning ... I can only say that pernicious means something negative.

I am not sure whether I really know what ostensible means. The context here indicates something relative to 'excuse' because all the reasons listed here are actually excuses. But I feel that it is very difficult to identify the exact meaning. I think I need more information.

I did not think much about the words' usage. I spent all my effort inferring the words' meaning, and did not bother to think how the words can be used because it was not required, and I thought ... I don't have relative information about word usage.

\subsection{Connectionist Perspective}

Another issue that can help explain why dictionary-induced vocabulary learning promotes better word learning than inferencing comes from the cognitive science perspective of connectionism. From this perspective, the complexity of connections that make up the networks of the target words are beneficial to learning (Moonen et al. 2006), and the rich information of dictionary entries for target words can offer complexity of connections when multiple aspects of 
knowledge are consulted, whereas the insufficiency of information availability of lexical inferencing is inferior in this respect.

A network consisting of connections (features) among units, in the literature on connectionist models of second language acquisition, refers to the concept of knowledge (Ellis 2003). The term feature is defined in the connectionism literature as a specific connection among units or, in cognitive terminology, a specific pattern of neural activation over a number of neurons (Westhoff 2004, Moonen et al. 2006, Moonen et al. 2014). Every word can be regarded as a union of various features that determine it in a unique way (Zareva and Wolter 2012). And networks involving numerous and varied types of features are more likely to become activated (Moonen et al. 2006). In other words, networks that consist of a greater variety of features concerning target words, such as morphological, sensory or pragmatic, are more likely to be activated than those made up of fewer features. Moreover, the number and variety of features of target words, which reflect the complexity of connections that make up the networks of target words, play a significant role in promoting the learning of target words (Moonen et al. 2006, Moonen et al. 2014).

As the mental actions of dictionary consultation involve more, and more varied, feature categories of the target words than those of inferencing, the networks of the target words constructed by the subjects doing reading comprehension and dictionary consultation consist of more different types of features and are thus more easily activated than the networks constructed by the subjects doing reading comprehension and inferencing. Dictionary consultation thus led to better learning of the target words than inferencing. The following interview transcript of a subject doing reading comprehension and dictionary consultation, for example, demonstrates clearly that the availability of different types of features about a target word (pronunciation, spelling and meaning) provided the subject with the ability to identify the connections among different information units. These complex connections also worked to stimulate the activation of networks of this target word:

I am able to give the meaning of apprehensive because when I consulted its dictionary entry, I noticed that its pronunciation and the pronunciation of its first three letters 'a-p-p' sounded similar to the word 'haipa (worried)' in Chinese, and the word haipa (worried) is given as part of the definition for apprehensive. Thus, I thought about 'haipa (worried)' the moment I pronounced the word 'apprehensive'.

Many pieces of evidence like this can be identified from the interview transcripts of subjects doing reading comprehension and dictionary consultation (see Zou 2012, for details). Furthermore, the availability of different types of features about the target words through dictionary consultation not only gave subjects the ability to identify the connections among different information units, but also assisted in their making of such connections easy to activate. The following interview transcript of another subject illustrates that a network of 
rich connections was easy to activate:

I could give the meaning of 'ostensible' because I remembered clearly the phrase 'ostensible reasons'. The reading text used this phrase, and it is also an example phrase given by the dictionary entry. The example sentence is about 'ostensible reason', too. Um, I've encountered it three times, so it is easy for me to recall it.

It is therefore clear that more complex connections were involved in the networks of target words constructed by the subjects who did reading comprehension and dictionary consultation, and that these networks had a greater chance of being activated than those constructed by the subjects who did reading comprehension and inferencing, resulting in a higher degree of task effectiveness of the former than the latter.

In conclusion, as the mental actions that are induced by reading comprehension and dictionary consultation involve more, and more varied, feature categories of the target words than those that are induced by reading comprehension and inferencing, the networks of the target words constructed by the subjects who did reading comprehension and dictionary consultation consist of more different types of features and are thus more easily activated than the networks constructed by the subjects who did reading comprehension and inferencing. Subjects who consulted the dictionary, therefore, had better learning of the target words than those who inferred the meanings. Given such differences, I suggest a change of the involvement load allocated to these two approaches to search. Search induced by dictionary consultation is strong as it entails the processing of multiple categories of word knowledge and involves great complexity of connections that make up the network of target words. Search induced by inferencing is moderate as it induces a lesser degree of elaboration and involves a more limited complexity of connections.

\section{Implications}

The results of this study demonstrate that the provision of a number of various aspects of knowledge about a target word is very facilitative for word learning. This is inferred from the finding that the reading comprehension and dictionary consultation task was significantly more effective than the reading comprehension and inferencing task because the former provided subjects with more knowledge aspects of the target words. It was the provision of various knowledge aspects that gave subjects a greater degree of elaboration for the target words, and it was noted that rich information offered better chances for subjects to build up networks of target words as a greater complexity of connections was available.

Providing learners with various aspects of word knowledge is crucial to word learning. It follows that language learners should be given access to various knowledge aspects of target words so as to assist them in processing those words from diverse dimensions and making use of more complex connections 
to build up networks regarding them. Self-learners are advised to attempt to obtain a variety of aspects of word knowledge they wish to learn rather than concentrating only on a sole aspect such as meaning. Access to a variety of information for individual words is typically provided in learner's dictionaries, so learners are suggested to make more use of dictionaries in their self-learning. To better promote this, dictionary training is also essential, as realization of the benefits of dictionary use and proficient dictionary skills can help users fully utilize the rich information provided in dictionaries.

Teachers are advised to provide learners with various aspects of knowledge about target words when inferencing exercises are done. The very nature of inferencing exercises means that incorrect meanings can be arrived at by a student, and that even if the correct meaning is inferred, a student may not be certain that it is indeed correct. Classroom feedback for inferencing exercises is typically constrained to the context in which the word is encountered in the exercise, leaving aside further knowledge aspects beyond that specific context, such as pronunciation, typical collocations, or how it can be used in other contexts. Thus, it is suggested that when inferencing exercises are done in class, teachers should also provide various kinds of information about the target words to students, rather than only providing information relevant to the context of the exercise.

\section{Conclusion}

The present research compares the effectiveness of two word-focused tasks: reading comprehension and dictionary consultation, and reading comprehension and inferencing. The results show that dictionary-induced vocabulary learning was significantly more effective than inferencing, based on which the involvement load hypothesis is suggested to be further developed in terms of its allocation of involvement load to different approaches to search.

Limitations of this research include the scope of study, the limited number of approaches to search investigated and the possible influence of experimental conditions. The two tasks studied here are also different to some extent and the text context may be not conducive to inferring the meanings of the target words. Moreover, the completion time of the two tasks are different, around 36 minutes for the reading comprehension and dictionary consultation and almost 29 minutes for the reading comprehension and inferencing. However, the influence of time on task effectiveness is uncertain as it is not the focus of the current research. Also, some previous studies showed negative correlation between time and word learning (e.g. Erten and Tekin 2008, Nakata 2008), some found positive correlation (e.g. Folse 2006, Keating 2008), yet others believed that time had no effect on task effectiveness (e.g. Chen 2002, Hill and Laufer 2003). It is suggested that future work take these limitations into account so as to improve the generalizability of results. 


\section{Acknowledgements}

I would like to thank Dr. Alice Chan, Dr. James Lambert and Dr. Haoran Xie for their invaluable help. Special gratitude also goes to the Editor, Danie Prinsloo, and the reviewers of Lexikos for their insightful suggestions for improvement. This article is based on part of my Ph.D. dissertation, which was submitted to City University of Hong Kong in 2012.

\section{References}

Abraham, Lee. 2008. Computer-mediated Glosses in Second Language Reading Comprehension and Vocabulary Learning: A Meta-analysis. Computer Assisted Language Learning 21(3): 199-226.

Carpenter, Shana, Riebana Sachs, Beth Martin, Kristian Schmidt and Ruxandra Looft. 2012. Learning New Vocabulary in German: The Effects of Inferring Word Meanings, Type of Feedback, and Time of Test. Psychonomic Bulletin E Review 19(1): 81-86.

Chan, Alice Yin Wa. 2011. The Use of a Monolingual Dictionary for Meaning Determination by Advanced Cantonese ESL Learners in Hong Kong. Applied Linguistics first published online November 8, 2011 doi:10.1093/applin/amr038. (Applied Linguistics 33(2): 115-140.)

Chan, Alice Yin Wa. 2012. Cantonese ESL Learners' Use of Grammatical Information in a Monolingual Dictionary for Determining the Correct Use of a Target Word. International Journal of Lexicography 25(1): 68-94.

Chen, Hongxia. 2002. Investigating the Effects of L1 and L2 Glosses on Foreign Language Reading Comprehension and Vocabulary Retention. Paper presented at the annual meeting of the ComputerAssisted Language Instruction Consortium, Davis, CA.

Chen, Yuzhen. 2010. Dictionary Use and EFL Learning. A Contrastive Study of Pocket Electronic Dictionaries and Paper Dictionaries. International Journal of Lexicography 23(3): 275-306.

Chen, Yuzhen. 2011. Dictionary Use and Vocabulary Learning in the Context of Reading. International Journal of Lexicography Int J Lexicography first published online December 2, 2011 doi:10. 1093/ijl/ecr031 (International Journal of Lexicography 25(2): 216-247.)

Chiu, Li-Ling and Gi-Zen Liu. 2013. Effects of Printed, Pocket Electronic, and Online Dictionaries on High School Students' English Vocabulary Retention. The Asia-Pacific Education Researcher 22(4): 619-634.

Coffey, Stephen. 2011. A New Pedagogical Dictionary of English Collocations. International Journal of Lexicography 24(3): 328-341.

Craik, Fergus I.M. 2002. Levels of Processing: Past, Present ... and Future? Memory 10(5-6): 305-318.

Craik, Fergus I.M. and Robert S. Lockhart. 1972. Levels of Processing: A Framework for Memory Research. Journal of Verbal Learning and Verbal Behavior 11(6): 671-684.

Craik, Fergus I.M. and Endel Tulving. 1975. Depth of Processing and the Retention of Words in Episodic Memory. Journal of Experimental Psychology: General 104(3): 268-294.

De Ridder, Isabelle. 2002. Visible or Invisible Links: Does the Highlighting of Hyperlinks Affect Incidental Vocabulary Learning, Text Comprehension, and the Reading Process? Language Learning and Technology 6(1): 123-146. 
Dziemianko, Anna. 2010. Paper or Electronic? The Role of Dictionary Form in Language Reception, Production and the Retention of Meaning and Collocations. International Journal of Lexicography 23(3): 257-273.

Eckerth, Johannes and Parveneh Tavakoli. 2012. The Effects of Word Exposure Frequency and Elaboration of Word Processing on Incidental L2 Vocabulary Acquisition through Reading. Language Teaching Research 16(2): 227-252.

Erten, İsmail Hakkı and Mustafa Tekin. 2008. Effects on Vocabulary Acquisition of Presenting New Words in Semantic Sets versus Semantically Unrelated Sets. System 36(3): 407-422.

Ellis, Nick. 2003. Constructions, Chunking, and Connectionism: The Emergence of Second Language Structure. Doughty, C. and M.H. Long (Eds.). 2003. Handbook of Second Language Acquisition: 33-68. Oxford: Blackwell.

Folse, Keith. 2006. The Effect of Type of Written Exercise on L2 Vocabulary Retention. TESOL Quarterly 40(2): 273-293.

Hill, Monica and Batia Laufer. 2003. Type of Task, Time-on-task and Electronic Dictionaries in Incidental Vocabulary Acquisition. International Review of Applied Linguistics 41(2): 87-106.

Hu, Hsueh-chao Marcella and Hossein Nassaji. 2012. Ease of Inferencing, Learner Inferential Strategies, and their Relationship with the Retention of Word Meanings Inferred from Context. Canadian Modern Language Review 68(1): 54-77.

Huang, Lo-li and Chih-cheng Lin. 2014. Three Approaches to Glossing and their Effects on Vocabulary Learning. System 44(1): 127-136.

Hulstijn, Jan. 1992. Retention of Inferred and Given Word Meanings: Experiments in Incidental Vocabulary Learning. Arnaud, P. and H. Béjoint. 1992. Vocabulary and Applied Linguistics: 113125. London: Macmillan.

Hulstijn, Jan and Batia Laufer. 2001. Some Empirical Evidence for the Involvement Load Hypothesis in Vocabulary Acquisition. Language Learning 51(3): 539-558.

Hulstijn, Jan, Merel Hollander and Tine Greidanus. 1996. Incidental Vocabulary Learning by Advanced Foreign Language Students: The Influence of Marginal Glosses, Dictionary Use, and Reoccurrence of Unknown Words. The Modern Language Journal 80(3): 327-339.

Keating, Gregory. 2008. Task Effectiveness and Word Learning in a Second Language: The Involvement Load Hypothesis on Trial. Language Teaching Research 12(3): 365-386.

Knight, Susan. 1994. Dictionary Use while Reading: The Effects on Comprehension and Vocabulary Acquisition for Students of Different Verbal Abilities. Modern Language Journal 78(3): 285-299.

Koyama, Toshiko and Osamu Takeuchi. 2004. How Look Up Frequency Affects EFL Learning: An Empirical Study on the Use of Handheld-electronic Dictionaries. Meng Chan, W., K. Nyet Chin, P. Martin-Lau and T. Suthiwan (Eds). 2004. Proceedings of the CLaSIC 2004 Conference: Current Perspectives and Future Directions in Foreign Language Teaching and Learning, 1-3 December 2004, Centre for Language Studies, National University of Singapore, Singapore: 10181024. Singapore: Centre for Language Studies, National University of Singapore.

Laufer, Batia. 2011. The Contribution of Dictionary Use to the Production and Retention of Collocations in a Second Language. International Journal of Lexicography 24(1): 29-49.

Laufer, Batia and Jan Hulstijn. 2001. Incidental Vocabulary Acquisition in a Second Language: The Construct of Task-induced Involvement. Applied Linguistics 22: 1-26.

Lew, Robert. 2012. How Can We Make Electronic Dictionaries More Effective? Granger, S. and M. Paquot (Eds.). 2012. Electronic Lexicography: 343-361. Oxford: Oxford University Press. 
Liu, Tzu-Chien, Melissa Hui-Mei Fan and Fred Paas. 2014. Effects of Digital Dictionary Format on Incidental Acquisition of Spelling Knowledge and Cognitive Load during Second Language Learning: Click-on vs. Key-in Dictionaries. Computers \& Education 70: 9-20.

Liu, Tzu-Chien and Po-Han Lin. 2011. What Comes with Technological Convenience? Exploring the Behaviors and Performances of Learning with Computer-mediated Dictionaries. Computers in Human Behavior 27: 373-383.

Luppescu, Stuart and Richard Day. 1993. Reading, Dictionaries, and Vocabulary Learning. Language Learning 43(2): 263-287.

Mestres-Missé, Anna, Thomas Münte and Antoni Rodriguez-Fornells. 2014. Mapping Concrete and Abstract Meanings to New Words Using Verbal Contexts. Second Language Research 30(2): 191-223.

Mondria, Jan-Arjen. 2003. The Effects of Inferring, Verifying, and Memorizing on the Retention of L2 Word Meanings. Studies in Second Language Acquisition 25(04): 473-499.

Moonen, Machteld, Rick de Graaff and Gerard Westhoff. 2006. Focused Tasks, Mental Actions and Second Language Learning: Cognitive and Connectionist Accounts of Task Effectiveness. International Journal of Applied Linguistics 15(2): 35-53.

Moonen, Machteld, Rick de Graaff, Gerard Westhoff and Mieke Brekelmans. 2014. The Multifeature Hypothesis: Connectionist Guidelines for L2 Task Design. Language Teaching Research 18(4): 474-496.

Nakata, Tatsuya. 2008. English Vocabulary Learning with Word Lists, Word Cards and Computers: Implications from Cognitive Psychology Research for Optimal Spaced Learning. ReCALL 20(01): 3-20.

Nassaji, Hossein. 2004. The Relationship between Depth of Vocabulary Knowledge and L2 Learners' Lexical Inferencing Strategy Use and Success. The Canadian Modern Language Review 61(1): 107-134.

Nassaji, Hossein and Hsueh-chao Marcella Hu. 2012. The Relationship between Task-induced Involvement Load and Learning New Words from Context. International Review of Applied Linguistics in Language Teaching 50(1): 69-86.

Nation, I.S.P. 2001. Learning Vocabulary in Another Language. Cambridge: Cambridge University Press.

Nation, Paul. 2015. Principles Guiding Vocabulary Learning through Extensive Reading. Reading in a Foreign Language 27(1): 136-145.

Paribakht, Sima and Marjorie Bingham Wesche. 1993. Reading Comprehension and Second Language Development in a Comprehension-based ESL Program. TESL Canada Journal 11(1): 9-29.

Prichard, Caleb. 2008. Evaluating L2 Readers' Vocabulary Strategies and Dictionary Use. Reading in Foreign Language 20(2): 216-231.

Pulido, Diana. 2009. How Involved are American L2 Learners of Spanish in Lexical Input Processing Tasks During Reading. Studies in Second Language Acquisition 31(01): 31-58.

Sadoski, Mark, Ernest Goetz and Maximo Rodriguez. 2000. Engaging Texts: Effects of Concreteness on Comprehensibility, Interest, and Recall in Four Text Types. Journal of Educational Psychology 92(1): 85-95.

Salsbury, Tom, Scott Crossley and Danielle McNamara. 2011. Psycholinguistic Word Information in Second Language Oral Discourse. Second Language Research 27(3): 343-360. 
Webb, Stuart and Anna Chang. 2015. How Does Prior Word Knowledge Affect Vocabulary Learning Progress in an Extensive Reading Program. Studies in Second Language Acquisition 37(04): 651-675.

Westhoff, Gerard. 2004. The Art of Playing a Pinball Machine. Characteristics of Effective SLAtasks. Babylonia 12(3): 58-62.

Zareva, Alla and Brent Wolter. 2012. The 'Promise'of Three Methods of Word Association Analysis to L2 Lexical Research. Second Language Research 28(1): 41-67.

Zou, Di. 2012. A Study of the Components of the Involvement Load Hypothesis: How Involvement Load Should be Allocated to "Search" and "Evaluation". Unpublished Ph.D. Dissertation. Hong Kong: City University of Hong Kong.

Zou, Di. 2016. Vocabulary Acquisition through Cloze Exercises, Sentence-writing and Composition-writing: Extending the Evaluation Component of the Involvement Load Hypothesis. Language Teaching Research 1362168816652418, first published on June 8, 2016 doi:10.1177/ 1362168816652418 . 
Appendix 1: Materials for Task 2

\section{Dealing with Procrastination}

Procrastination refers to the act of delaying the work you should do to a later time. It is wasting time when you have some work to do, but choose not to do it early.

Most procrastinators do not feel that they are doing this on purpose. Instead, they feel that they really tried to do the work. But they could not start because there are too many things out of their control. So they have a long list of ostensible reasons, such as "I did not have time", "I had to attend a wedding" or "I had other important things to do". However, these surface reasons are not true.

When procrastination becomes a habit, it is pernicious. If you procrastinate, you may often find yourself not having enough time to do a satisfying work. This can make other people unhappy and get a bad impression of you. Habitual procrastination can even damage your friendships. As you always renege on your promises to complete work on time, your friends may no longer trust you. Thus it is very necessary to know the causes of procrastination and leam to deal with it

Procrastination is often caused by a real or imagined fear or worry. For instance, you might delay preparing for an oral presentation, because you are apprehensive that you will not be able to remember the entire speech. You may be so worried about doing a bad job that you decide not to work on it until the last minute.

Being a perfectionist is a main trait that causes fear and anxiety. When you imagine yourself making an English presentation, are you comparing yourself to great speakers? Or are you picturing that others taunt you about your accent? Rather than worry yourself with these thoughts, think of specific ways to improve the performance, may help to lessen performance anxiety.

"Lack of motivation" may also cause procrastination. If you are forced to teach a subject you are not interested in, you may find yourself wasting time instead of being assiduous. Even if you know that the subject can help you get a good job, you will not work hard. It is not easy to think carefully about something you have no interest in.

Feelings of lassitude can cause procrastination, too. This often happens when you keep on pushing yourself very hard without getting any rest. If so, you may experience a state of tiredness and feel unable to focus on any work. Learning to bal ance your time can be helpful in preventing this.

Sometimes you put off doing something because you do not know how to do it. For example, if you start doing a job that requires collecting data and creating graphics, having the right skills is indispensable. Knowing how to do a task before you begin it is very important. Sometimes it is difficult to ask for help and sometimes it is even harder to realize that you need help. Being able to divulge personal limitations and ask for help is a skill we need to learn.

1. ostensiblemeans:

2. pernicious means:

3. renege means:

4. apprehensivemeans:

5. trait means:

6. tauntmeans:

7. assiduous means:

8. lassitudemeans:

9. indispensablemeans:

10. divulgemeans: 